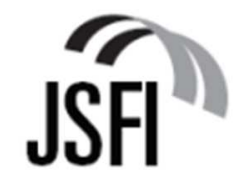

Game Theory and Corporate Governance: Conditions for Effective Stewardship of Companies Exposed to Climate Change Risks

\begin{tabular}{|r|l|}
\hline Journal: & Journal of Sustainable Finance and Investment \\
\hline Manuscript ID & 16-JSFI202-SI.R1 \\
\hline Manuscript Type: & Special Issue Paper \\
\hline Keywords: & Engagement, Stewardship, Divestment, Stranded Assets, Game Theory \\
\hline \multicolumn{2}{|l}{} \\
\hline
\end{tabular}

SCHOLARONE ${ }^{\text {TH }}$

Manuscripts 


\title{
Game Theory and Corporate Governance: Conditions for Effective Stewardship of Companies Exposed to Climate Change Risks
}

\begin{abstract}
Engagement between investors and corporate boards has been suggested as a pathway to mitigate stranded asset and climate change risks. Debate is ongoing as to whether divestment or active ownership strategies are more appropriate to deliver long-term value and environmental sustainability. This paper tests the effectiveness of owner engagement strategies by studying the conditions for cooperation between investors and their companies.

Characteristics of investors and companies are modelled in game theory frameworks, informed by semi-structured interviews with professionals from the energy and finance industries, and academia, $\mathrm{NGO}$, and regulatory sectors. Conditions for mutual cooperation between investors and companies are characterized as prisoners' dilemmas. A number of parameters are examined for their impact on the development of sustained cooperative equilibria, including: the benefits and costs of cooperation; the degree of strategic foresight; individual discount factors; and mutual history. Challenges in the formation of investor coalitions are characterized and solution concepts discussed.
\end{abstract}

Key Words: Engagement, Stewardship, Divestment, ESG, Stranded Assets, Game Theory 


\section{Introduction}

Climate change is rapidly becoming a material investment risk. Recent work by the Carbon Tracker Initiative (CTI) (e.g. 2013; 2014), McGlade \& Ekins (2015), the University of Oxford Smith School of Enterprise and the Environment (e.g. Caldecott et al. 2013; 2015), HSBC (e.g. Paul Spedding et al. 2013), Standard \& Poor's (2013; 2015), Kepler Cheuvreux (Lewis \& Voisin 2014), and others have made stranded assets and misallocated capital a key concern of owners of fossil fuel companies. Universal owners are also gaining awareness of undiversifiable climate change value-at-risk (Covington \& Thamotheram 2015; The Economist Intelligence Unit 2015). Investors must employ stewardship strategies to mitigate climate change risk on behalf of their beneficiaries. Professor Kay of the Kay Review (2012) observes that investors have only two options in their relationships with companies: divestment and engagement. Shareholder engagement and active ownership is becoming a popular tool for shareholders wishing to influence the behaviour of their companies (e.g. Orsagh 2014; Kim \& Schloetzer 2013 from pwc 2015; Goodman \& Fields 2015). A common application of shareholder engagement is the mitigation of environmental, social, and governance (ESG) risks of portfolio companies, such as those arising from climate change (Clark et al. 2014).

In July 2012, climate activist Bill McKibben popularised fossil fuel divestment with an article in the Rolling Stone (2012). McKibben called on university endowments and pensions to divest from fossil fuel holdings, on the logic that these funds exist to allow their benefactors to enjoy a prosperous future free of the impacts of climate change. Modelled on the divestment campaign which placed economic pressure on apartheid South Africa, more than 501 institutions with collective assets worth over US\$3.4th have joined the Fossil Free divestment campaign, pledging either full or partial divestment of fossil fuel assets (gofossilfree.org 2015). Ansar et al. (2013) argue that the greatest impact of the divestment campaign might be the stigmatisation of fossil fuel companies.

In their dissenting opinions on fossil fuel divestment, Harvard University (Faust 2013), The Wellcome Trust (Farrar 2015), and the Expert Group of the Norwegian Ministry of Finance (Skancke et al. 2014) all cite active ownership as their preferred management strategy for climate change risks. Divestment and engagement strategies now stand at odds with one another. Central to this debate is the question of what effect, if any, divestment (i.e. exclusion from a universe of investible securities) might have on the actions or outcomes of a company or class of companies. Alternatively, what effect might shareholder engagement and active ownership have on a company's actions or outcomes? Under what conditions might shareholder engagement be effective?

Despite a growing interest from investors in climate change risk management, approaches to these questions have been unsophisticated so far. Divestment decisions have been made largely on the grounds of ethics and mission-alignment of funds, belied by the prominence of faith-based groups and charitable foundations among divesters (gofossilfree.org 2015). Engagement on climate change risk has either focussed on supplementary disclosure (e.g. CDP) or targeted initiatives with extractive companies (e.g. the Aiming for A coalition). There is a demonstrated need for investors to be able to identify conditions for effective stewardship, to make intelligent and systematic engagement and disinvestment decisions corresponding to underlying environment-related risks.

This paper examines the relationships between the management and equity owners of companies exposed to climate change risks. Characteristics of companies and shareholders which are deterministic in divestment or engagement decisions over carbon risk are identified and parameterized. Game theory concepts are applied to the relationships between companies and equity owners, and elementary models are developed to explore dynamics of engagement strategies. This 


\section{Submission to Journal of Sustainable Finance and Investment}

work is informed by semi-structured interviews with professionals in the oil and gas industry, the financial industry, and NGO, regulatory, and academic sectors.

\section{Methodology}

This paper examines how investors and companies might interact with each other to mitigate climate change risks. The subject of study is the decision making processes of both oil and gas companies and their investors, and critically how their decisions influence each other. The study of how individuals or organizations (hereafter called agents) make decisions is called decision theory.

Decision theory is the study of how a single rational agent maximizes their outcome, especially under uncertainty, and has found application among engineers, economists, psychologists, computer scientists, and policy makers (Hansson 2005). Decision theory has its origins in Expected Utility Theory proposed by Daniel Bernoulli in 1738 (translated 1954). Mesterton-Gibbons (2000) provides a highlevel overview of decision theory domains based on the number of agents and the number of rewards they receive, adapted in Figure 1. As the decisions and outcomes of investors and their companies are clearly interrelated, game theory tools will be used to examine the decision making of various agents.

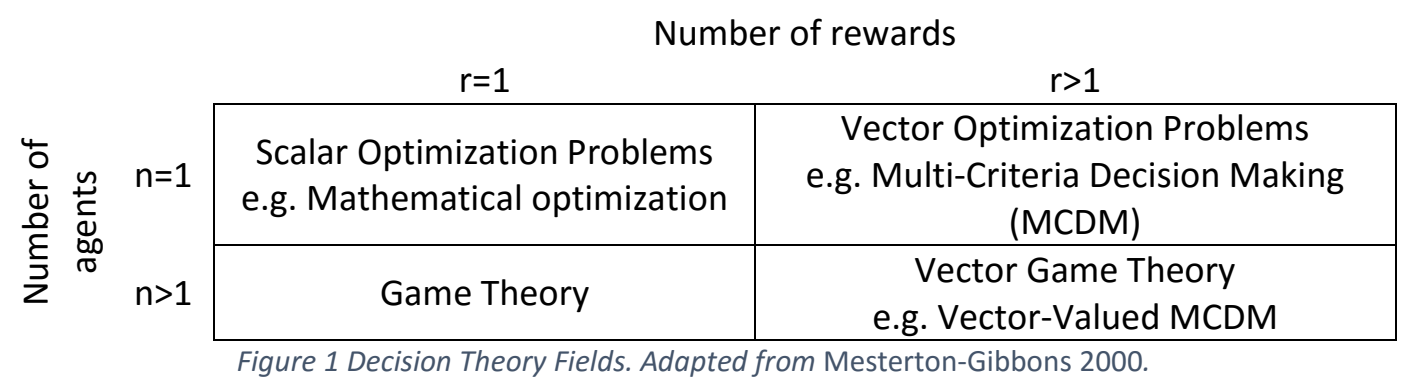

Game theory is the mathematical study of strategic decision making. Classical Forms are those first described by Von Neumann and Morgenstern (1944) and bolstered substantially by Nash (e.g. 1950), and a number of other economists writing in the 1950s and 60s. Metagame analysis was invented by Howard (1971), citing a need to develop strategic analysis tools which are easier to understand and are more descriptive of real agent behaviour. Axelrod in the 1980s (e.g. 1980; 1984) rekindled an interest in the field by realizing its potential to study problems of social coordination and cooperation. Smith (1982) was influential in introducing the subject to evolutionary biology. Game theory and its derivative disciplines now span diverse fields ranging from law and economics to computer science and artificial intelligence.

Game theory is used to identify equilibria solutions from which no player is likely to deviate. Various equilibrium concepts exist, differing, for example, in their treatment of rationality, their stability in repeated play, and robustness to diverse agent beliefs. In the following section, classical normal form games are used to examine conditions for effective stewardship. The equilibria developed provide insight into effective engagement strategies between investors and their companies. Challenges of coalition formation among investors are also explored. Table 1 describes equilibria forms used in this paper.

Table 1 Selected classical form equilibria. Adapted from Gibbons (1992)

Solution Concept $\quad$ Description

Nash equilibria are a set of strategies chosen by agents wherein no agent can

Nash Equilibrium strictly improve their utility by choosing any other strategy given the strategies of the other agents; all agents are playing best responses to each other 

best responses to the expected strategies of the other agents

\section{Game Theory Models}

\subsection{Social Dilemmas between an Investor and a Company}

Engagement between an investor and a company on an ESG issue is characterized as a social dilemma. A social dilemma occurs when agents individually seek higher payoffs for antisocial behaviour to the detriment of their collective interests (Dawes 1980). The prisoner's dilemma is the canonical social dilemma and is used in this section to explore interactions between two agents.

A 1v1 iterated prisoner's dilemma (IPD) is developed as a representation of the interaction between an investor (or a coalition of investors) and a company. In such a scenario, a cooperative outcome is one in which an investor engages on an ESG issue of interest, and the company delivers a corresponding change in behaviour. This is the socially optimal outcome wherein the investor and the company management both benefit from the financial out-performance of successful engagement, as demonstrated by Dimson et al. (2012) and Eccles et al. (2012). A non-cooperative outcome is one in which the company, the investor, or both fail or refuse to deliver on their engagement. An investor may lose interest in the subject or even divest from the company, and a company board may defect from its commitment to the investor. Characteristic of the IPD, the reward of mutual cooperation vests continually over time, whereas the temptation to defect delivers immediate utility to that agent followed usually by less cooperative future outcomes (e.g. Gibbons 1992). A brief development of the IPD parameterization follows. An extensive mathematical description of the methodology used is available in Appendices $A$ and $B$.

The prisoner's dilemma was introduced by Dresher \& Flood in 1950 to model strategic options during the cold war (Aumann et al. 1964). It is reproduced in its familiar form in Figure 2 . Among other $2 \times 2$ games, the prisoner's dilemma is described by its ordered preferences: $T>R>P>S$, leading to the non-cooperative Nash Equilibria (defect, defect).

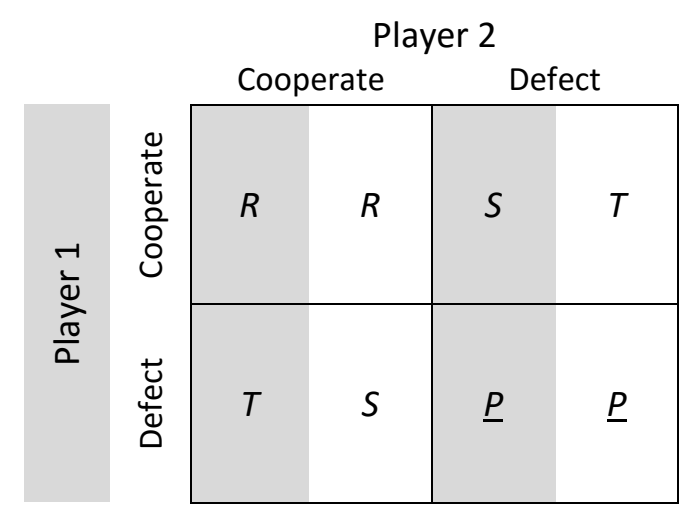

Figure 2 1v1 Prisoner's dilemma payoffs in matrix form with Nash Equilibrium underlined.

The uncooperative Nash Equilibria is dissatisfying for its failure to predict the cooperative equilibria regularly observed between real individuals and organizations (e.g. Fehr \& Fischbacher 2003; Pothos et al. 2011). Repeated interactions between agents have the potential to create conditions of trust and mutual cooperation, resulting in improvements in both private outcomes and overall system efficiency (Kreps et al. 1982; Axelrod 1984). In this section, a mixed-strategy IPD is used to develop Bayesian Nash Equilbrium, per Harsanyi (1973), with bayesian inferences and evolutionary decision making as in Goeree \& Holt (1999). 


\section{Submission to Journal of Sustainable Finance and Investment}

Variables examined in this model include the benefits and costs of cooperation, discount factors of the agents, and foresight and memory horizons. Table 2 describes how these parameters may be interpreted as conditions for cooperation between companies and investors and how IPD payoffs are simplified to a cost and benefit framework.

\section{Table 2 IPD Parameterization}

\begin{tabular}{|c|c|c|}
\hline Parameter & Symbol & Interpretation \\
\hline Benefit & $B E N=[1 \ldots 10]$ & $\begin{array}{l}\text { Benefit of cooperation, e.g. financial outperformance of } \\
\text { company, mitigation of asset and reputation risk, talent } \\
\text { attraction, social licence to operate }\end{array}$ \\
\hline Cost & $\operatorname{COS}=\left[0 \ldots{ }^{B E N} / 2\right]$ & $\begin{array}{l}\text { Cost of cooperation, e.g. engagement personnel salaries, } \\
\text { opportunity costs, or reluctance, resistance, and laziness }\end{array}$ \\
\hline \multirow{4}{*}{ 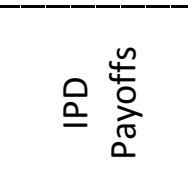 } & Temptation & $T=B E N$ \\
\hline & Reward & $R=B E N-C O S$ \\
\hline & Punishment & $P=0$ \\
\hline & Sucker & $S=-C O S$ \\
\hline $\begin{array}{l}\text { Discount } \\
\text { Factor }\end{array}$ & $\delta_{i}=[0 \% \ldots 100 \%]$ & $\begin{array}{l}\text { Decreased value of future payoffs relative to present payoffs, } \\
\text { or probability of game termination on subsequent round. }\end{array}$ \\
\hline Memory & $Q_{i}=[1 \ldots 10]$ & $\begin{array}{l}\text { Horizon of significance for past activity on which agents base } \\
\text { present beliefs }\end{array}$ \\
\hline Foresight & $L_{i}=\left[\begin{array}{lll}1 & \ldots & 10\end{array}\right]$ & $\begin{array}{l}\text { The number of iterations an agent foresees in the future for } \\
\text { which they calculate future-value payoffs }\end{array}$ \\
\hline
\end{tabular}

\subsection{Social Dilemmas between Multiple Investors}

An N-agent IPD (NIPD) is developed as a representation of the coordination between multiple investors. NIPD models are commonly used to examine challenges of free-riding and coordination in social dilemmas (e.g. Ray \& Vohra 1999). The NIPD is used here to examine the interest of investors in forming coalitions in their engagements with companies. See Appendix $\mathrm{C}$ for the full development of the NIPD.

It is more difficult to develop cooperative equilibria in an N-Agent IPD (NIPD) than in the 2-agent IPD, with the challenge increasing with the number of agents (e.g. Komorita 1976). In the NIPD, cooperative rewards are socialized to all agents, sanctions against non-cooperative agents have social externalities, and often elements of anonymity prevent agents from identifying cooperators and defectors (Dawes 1980). Example uses of the NIPD are to describe tragedy of the commons resource problems (Hardin 1968), endogenous coalition formation (Ray \& Vohra 1999), and energy and climate policy freeriding problems (Nordhaus 2015).

Investors seeking to form coalitions in their interactions with companies face a typical freeriding problem. Collectively they benefit from strong engagement with the company, but individually they would benefit from neglecting their responsibilities and freeriding on the efforts of others. Solution concepts to the NIPD must overcome both the short-termism temptation of the IPD and the freeriding temptation. Many solution concepts for the NIPD exist, including asymmetric payoffs (e.g. Manhart \& Diekmann 1989; Vyrastekova \& Funaki 2010), side payments (e.g. Ray \& Vohra 1999; Nordhaus 2015), spatial and personality interactions (Axelrod 1984), and social network theories (e.g. Rezaei et al. 2009).

The solution concept of Manhart \& Diekmann (1989) is adapted by relaxing the strict dominance of defection strategies by allowing agents to have asymmetric payoffs. This solution is well suited to 


\section{Results}

\subsection{Social Dilemmas between an Investor and a Company: The IPD} The IPD is resolved in order to examine how parameters in Table 2, which are proxies for the attributes of companies and investors, lead to mutual cooperation, which is used as a proxy for effective stewardship. The sustained mutual cooperation of investors and companies leads to long-term management of environment-related risks and financial outperformance.

\subsubsection{Dependence on Payoffs and Discount Factors}

The first parameters examined as conditions for effective stewardship are payoffs and discount factors. The payoffs for effective stewardship generally capture the benefits of financial outperformance of the company and the mitigation of environment-related risk less the costs of engagement. The defection of either the company or the investor allows them to capture the benefit of stewardship without the costs but may lead to less cooperative outcomes in the future.

Holding other factors constant, payoffs and discount factors are varied to explore their influence on conditions of mutual cooperation, shown in Figure 3. Benefits and costs need only be defined relative to each other; integer values are chosen on a range of 1 to 10. Discount factors are chosen on intervals between $0 \%$ and $100 \%$.

The discount factor is used as a proxy for the discount rate used in discounted cash flow analysis by investors or companies (up to approximately 20\% (Haldane \& Davies 2011)). As a proxy however, the discount factor can also be used to capture excessive discounting and short-termism (an additional $5 \%$ to $10 \%$ (Haldane \& Davies 2011)) or the likelihood that an investor will sell their position within the year (>100\% for US and UK, based on average stock holding time (Bogle 2010)).

\begin{tabular}{|c|c|c|c|c|c|c|c|c|c|c|}
\hline \multicolumn{11}{|c|}{ Mutual Cooperation [\%] } \\
\hline 0 & 10 & 20 & 30 & 40 & 50 & 60 & 70 & 80 & 90 & 100 \\
\hline
\end{tabular}



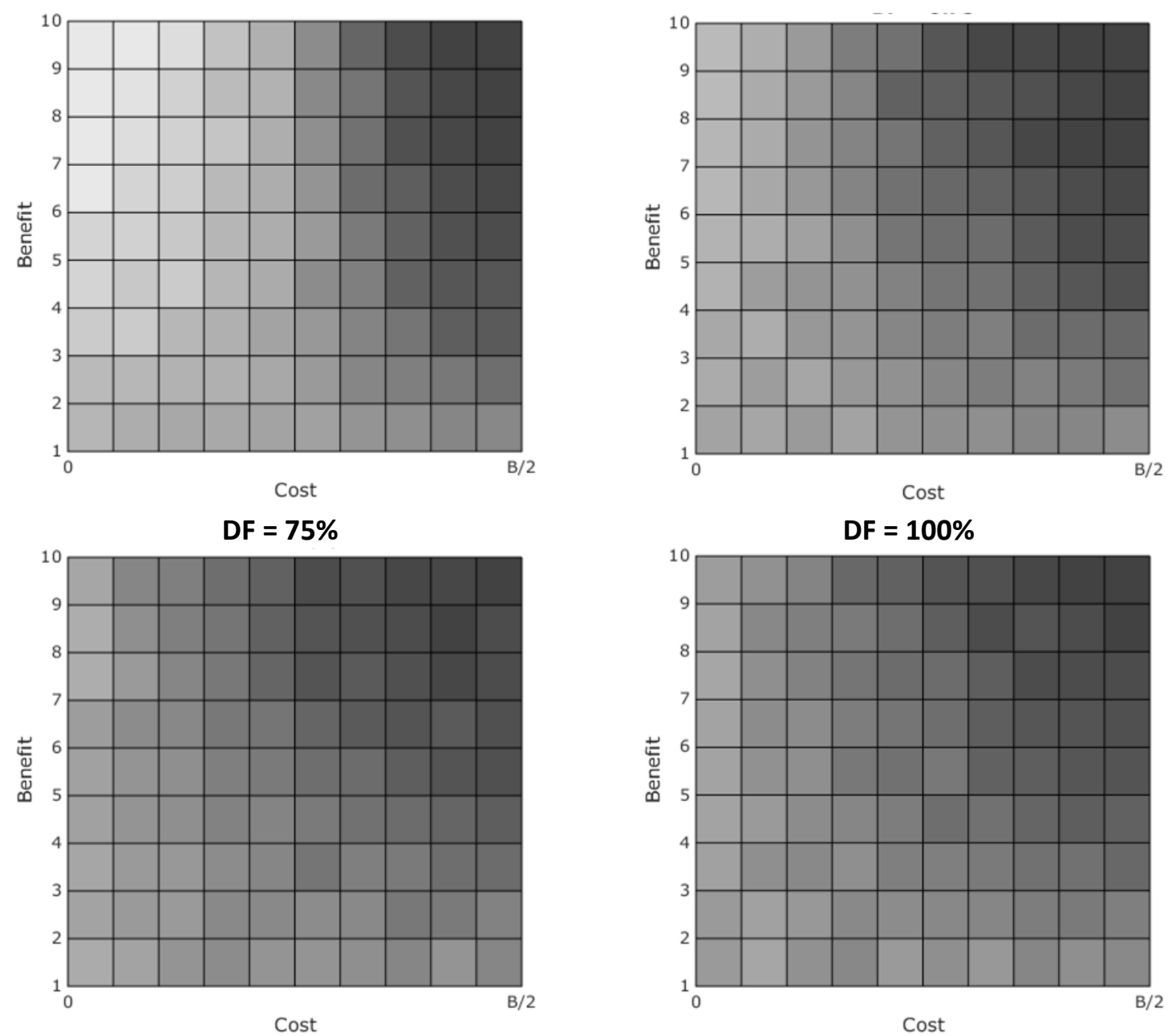

Figure 3 Modelled dependence of mutual cooperation on payoff and discount factors.

Conditions for cooperation are strongest between an investor and a company when the benefit of cooperation is large, and the cost of cooperation is small. The social dilemma aspect of the game makes costs much more deterministic in cooperative outcomes than benefits. In engagements between companies and investors, it is critical therefore, that both parties feel a strong benefit from engaging with each other and have minimal costs for doing so.

Low discount factors for both investors and companies encourages mutual cooperation. Agents with low discount factors place larger weights on future payoffs. For investors and companies in shareholder engagements, it is crucial that they have a low discount factor as the benefit of their engagement activities must vest continually to exceed the short-term payoff of defection.

Section 5 develops a more critical discussion of these findings.

\subsubsection{Dependence on Memory and Foresight Horizons}

Keeping other factors constant at conditions for high mutual cooperation, horizons of memory and foresight are varied to explore their influence on the development of mutual cooperation, shown in Figure 4. 


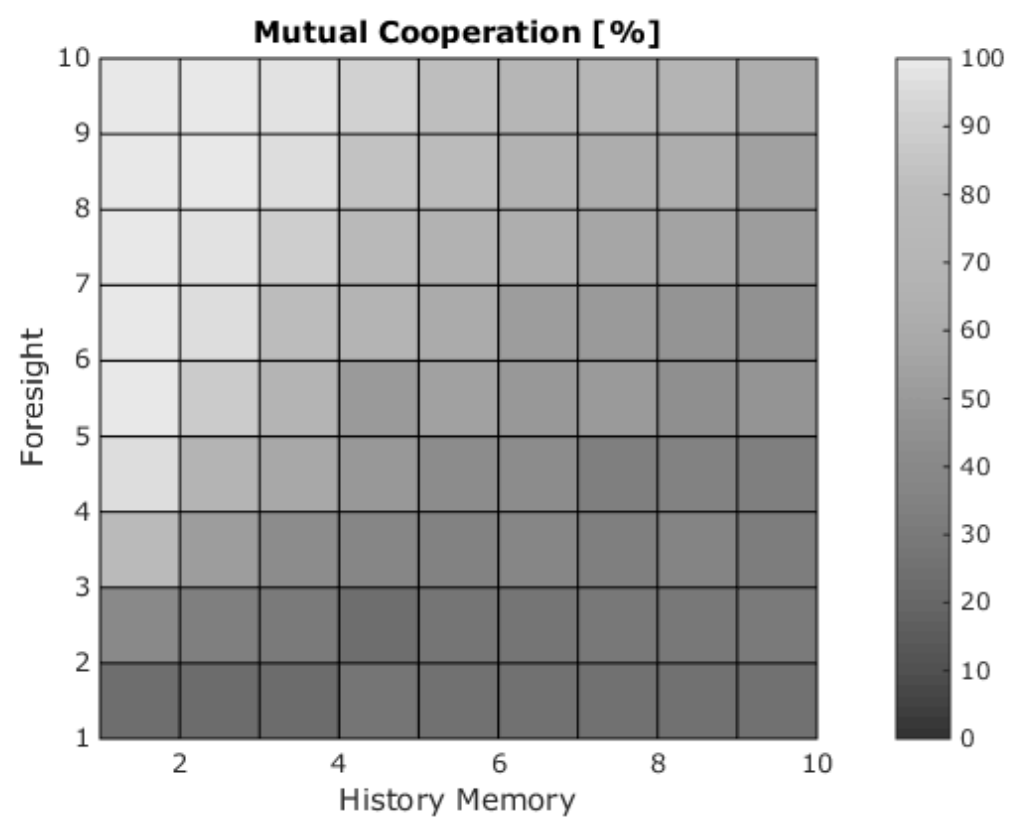

Figure 4 Modelled dependence of mutual cooperation on degree of foresight and history memory.

With a low foresight horizon, it is difficult to establish conditions of mutual cooperation. Closely related to discount factor, the foresight of investors and companies is deterministic in whether they engage or not. While a discount factor examines the weight that agents give to future payoffs, foresight determines whether they consider the value of those future payoffs at all.

Even with longer foresight horizons, mutual cooperation may be hindered by long memories of past history. A longer memory in this sense allows agents to recall past defections which quickly eliminate any potential for present cooperation. Memory horizons indicate the significance of consistency in cooperation, showing that past defections can be deterministic in present cooperation.

Further insights are developed in Section 5. 


\subsection{Social Dilemmas between Multiple Investors: The NIPD}

The NIPD is resolved in order to examine how parameters in Table 3, which are proxies for the attributes of investors, lead to mutual cooperation, which is used as a proxy for coalition formation. The sustained mutual cooperation of investors leads to the long-term formation of a coalition to engage on the management of environment-related risks.

\subsubsection{Free-riding Temptation}

Figure 5 shows average freeriding and cooperation of fifty agents in an NIPD over successive iterations. The left plots map the defector and cooperator payoffs dependent on the proportion of agents cooperating. The right plots are the probability density distributions of cooperating agents. Even under these relaxed conditions, cooperative equilibria remain elusive. The smaller the difference between payoffs for freeriding and cooperating, the higher the participation in the cooperative coalition.
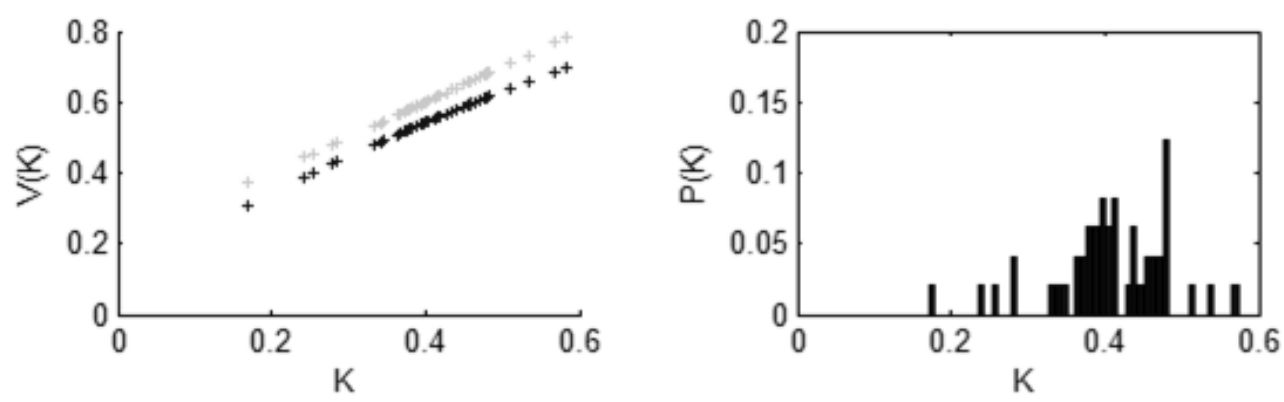

$$
\begin{aligned}
& T=K+0.2 \\
& R=1 * K^{\prime 2} / 3
\end{aligned}
$$
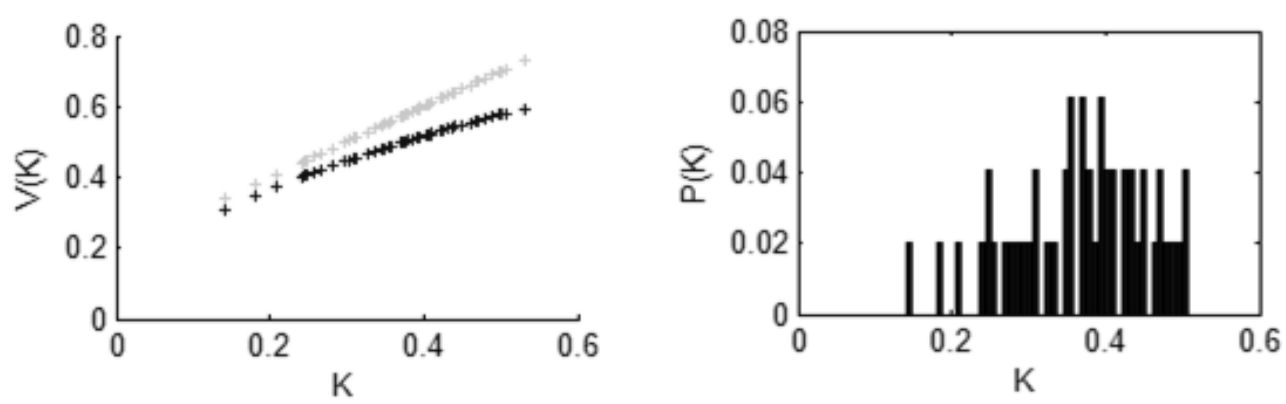

$T=K+0.2$ $R=\frac{2}{3} * K^{\prime 1 / 2}$
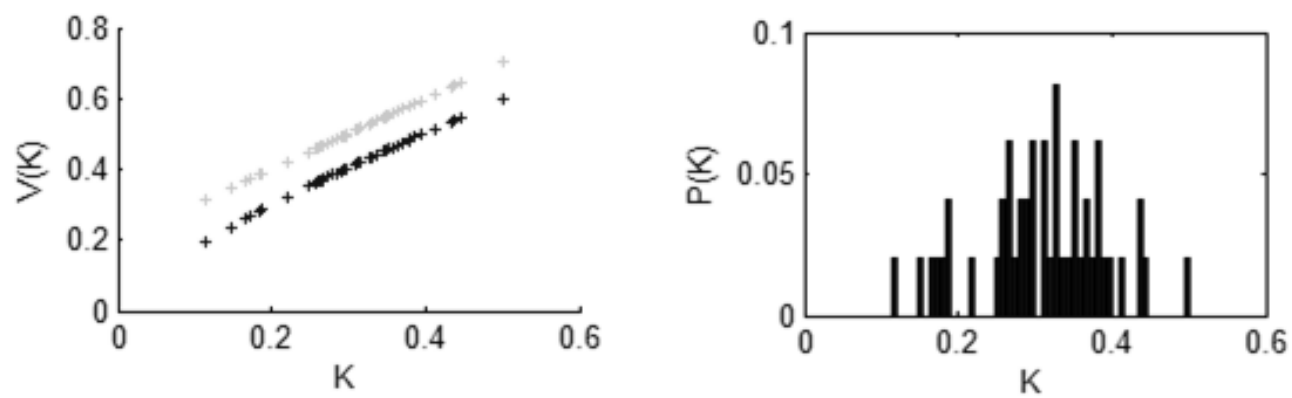

$$
\begin{aligned}
& T=K+0.2 \\
& R=1 * K^{\prime 3 / 4}
\end{aligned}
$$
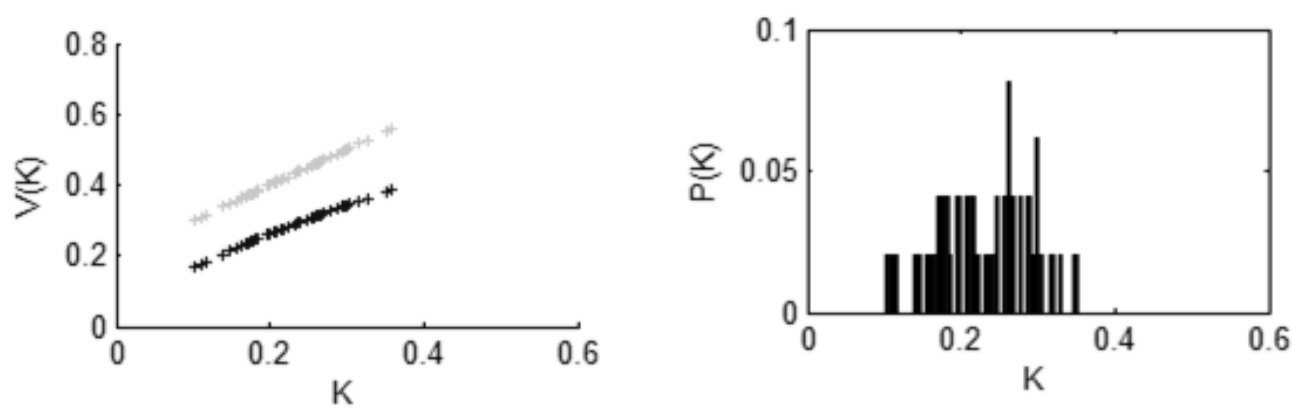

$T=K+0.2$

$R=\frac{2}{3} * K^{\prime 2} / 3$

Figure 5 Freeriding temptation under various payoff profiles. 


\subsubsection{Cooperation Dependence on Weighting}

Figure 6 shows, for a number of defection payoffs $(D)$, that larger-weighted agents (i.e. investors with larger holdings) are more likely to cooperate with one-another. This reflects how large institutional investors have been the first to join ethical-based investors in engaging on climate change risks - the 'Aiming for A' coalition, for example, includes 23 pension funds in addition to 32 charity, foundations, and church groups (Aiming for A 2015). It must be noted that diminishing the defection payoff bonus (D) results in the violation of the strict ordinality of the temptation payoff $(T)$ and the reward payoff $(\mathrm{R})$, as required by Equation 18, Appendix C.

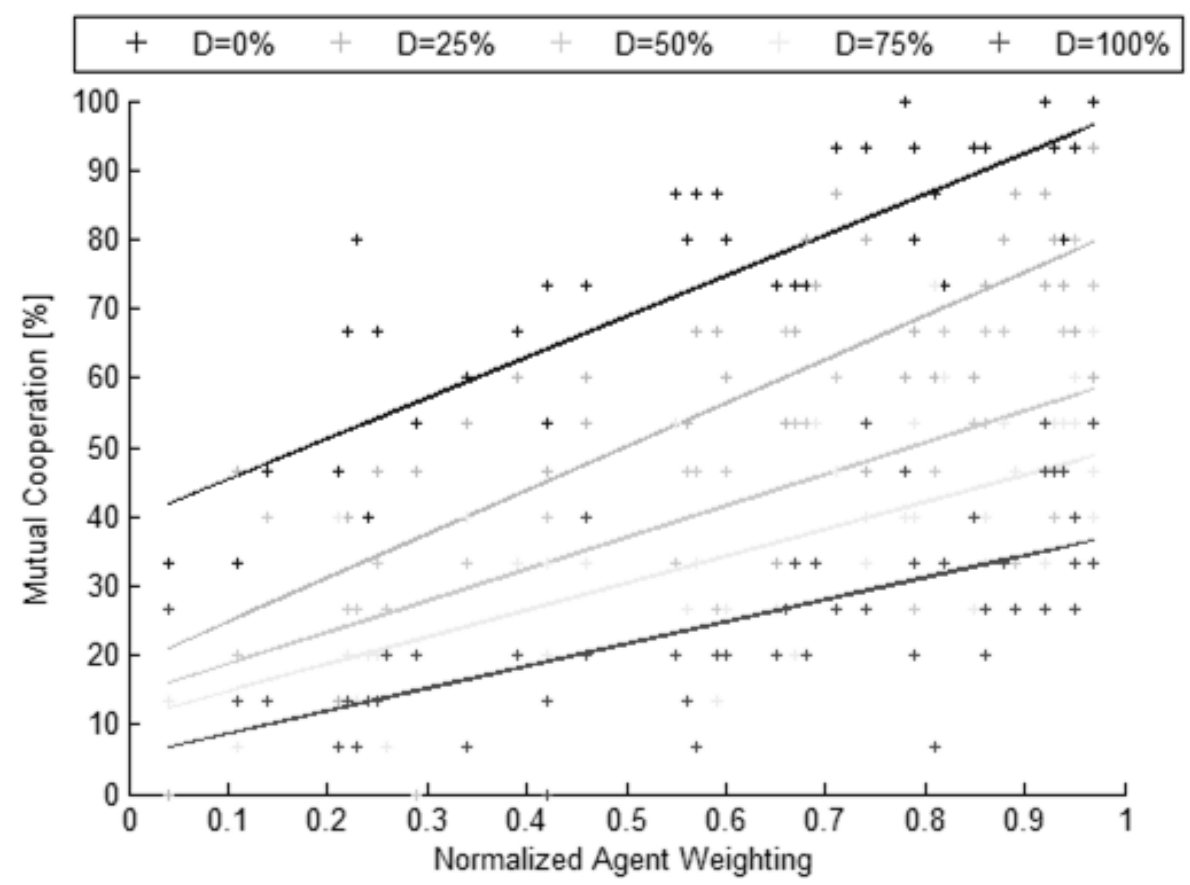

Figure 6 Cooperation dependence on agent weighting subject to various defection payoffs.

Further commentary is provided in Section 5. 
Likewise investors can demand incremental progress which is not as immediately burdensome to company directors. The dominance of costs in cooperative equilibria may help explain why passive investors, who operate tight business models, have been reluctant to join stewardship efforts (Wong 2010; Johnson 2015). One finance industry contributor suggests:

\section{'I think [engagement is] a challenge for the passives because they're pressed hard on} fees.'

The IPD shows how the long memories of agents diminish the chance for a cooperative equilibria. This indicates that prior defections can be detrimental to current engagement efforts. Investors should then seek consistent small improvements from their companies with sustained engagement over successive years, rather than rapid change and adaptation. This was the strategy employed by Aiming for A, whose landmark shareholder proposals regarding climate change risk passed in 2015 after years of engagement (PIRC 2015). One finance industry contributor describes their engagement approach:

'It's been a very strategic approach, the resolutions didn't come out of the blue, we built extremely good relationships, [the companies] know us, they know where we're coming from.'

Large foresight horizons are shown to be necessary for cooperative equilibria. Foresight horizons are related to discount factors, but represent instead the horizon beyond which a decision maker has no ability or interest to foresee a payoff. Oil and gas company executives have an average tenure of 4.5 


\section{Submission to Journal of Sustainable Finance and Investment}

years (Reinsvold 2015), with performance incentives usually vesting three years after (Alvarez \& Marsal Taxand LLC 2015). It is possible that the reluctance of companies to engage on climate change risks is explained by the bounded near-term foresight horizon of company executives. NGO and finance industry contributors describe executive preoccupation with short term results:

\section{'The company is so tied to that quarterly earnings call ... which makes it really hard to think long term and strategically'}

'We're not just interested in value over the next three months- we're interested in multiple decades of owning some of these key holdings. We need bring this perspective to companies and CEOs who may have a much shorter cycle.'

The existence of a foresight horizon may also help explain why passive investors are reluctant to engage in stewardship activities. Their belief in efficient or near-efficient markets may preclude their interest in any foresight horizon as part of their investment strategy.

The NIPD is known to be a more frustrating social dilemma than the IPD, and increases in difficulty with the number of agents (Komorita 1976; Dawes 1980). Shareholders may have a large potential influence with companies, but only when they are coordinated. Per one energy industry contributor:

\section{'Shareholders are incredibly powerful... what you need to see is a significant weight of shareholders getting behind [this view].'}

Even with the enhanced cooperation payoffs of the NIPD model above, wide-spread cooperation of the agents is rare. Oil and gas companies in particular have massive disparate shareholder bases numbering in the hundreds of thousands of holders (e.g. BP plc 2014). However the number of significant shareholders is much less. Less than ten individual shareholders often control a disproportionate amount of oil and gas companies - over twenty percent (e.g. BP (2014), Total (2015), Shell (2015), ExxonMobil (Yahoo! Finance 2015b) and Chevron (Yahoo! Finance 2015a)). An engageable number of shareholders might control a dominating interest in an oil and gas company.

Additional NIPD mechanisms may present concepts for the formation of coalitions among shareholders. Resource allocation and side payment mechanisms (e.g. Shenoy 1979; Nordhaus 2015) are familiar game theory subjects which allow agents to come to terms among each other for increased cooperation. This is already in practice by investors, for instance PRI's use of a clearing house mechanism to allocate support and resources to engagements by fellow investors (PRI 2015). One interviewee involved in an engagement coalition described the use of shared costs and responsibilities to maximize impact across a portfolio of companies in a structure similar to a social network game. These coalitions are still subject to free-riding, but cost sharing among cooperative investors enables easier coalition formation.

\section{Conclusion}

In this work, non-cooperative social dilemma games were used to develop insight into the conditions for effective stewardship of companies by their investors. Iterated prisoners' dilemmas were used explore conditions for mutual cooperation between pairs and groups of agents. The games and insights developed were informed by semi-structured interviews with energy and finance industry professionals and NGO/regulator/academic sector professionals.

Several barriers to mutual cooperation and coalition formation in engagements are identified, including the disproportional impact of costs relative to benefits, low discount factors, short foresight horizons, and sensitive memories. Free-riding temptations increase in larger groups, making coalition 
formation among large groups of shareholders difficult. Novel solution concepts like side payment and social network mechanisms can inform the development of structures for stable coalitions of investors.

The long-term interests of asset owners are driving sustainability performance in their investee companies in order to mitigate exposure to environment-related risks. For investors interested in influencing company behaviour, challenges remain in overcoming short-term defection between investors and company boards. Conditions for mutual cooperation have been developed in this paper to give investors insight as to when their engagements of sustainability issues will be more effective. Investors seeking to build stable coalitions with other investors must overcome free-riding incentives to wield stronger influence with companies.

This work offers investors additional insight for making engagement, disinvestment, and divestment decisions. The ultimate significance of this work is that engagement and divestment decisions may eventually be made empirically, based on underlying environment-related risks and the effectiveness of investor stewardship and engagement.

\section{Acknowledgements}

The authors extend their sincere thanks to the thirteen interviewees who informed the development of this work.

\section{References}

Alvarez \& Marsal Taxand LLC, 2015. Oil and Gas Exploration \& Production (E \& P) Incentive Plan Design Report, Available at: http://www.alvarezandmarsal.com/sites/default/files/am_tax_oilandgas_e-preport.pdf [Accessed September 3, 2015].

Ansar, A., Caldecott, B. \& Tilbury, J., 2013. Stranded assets and the fossil fuel divestment campaign, Smith School of Enterprise and the Environmen. Available at: http://www.smithschool.ox.ac.uk/research-programmes/stranded-assets/SAP-divestmentreport-final.pdf [Accessed April 3, 2015].

Aumann, R.J. et al., 1964. The bargaining set for cooperative games. in Dresher, Shapley, and Trucker, 52, pp.443-476.

Axelrod, R., 1980. Effective Choice in the Prisoner's Dilemma. The Journal of Conflict Resolution, 24(1), pp.3-25.

Axelrod, R., 1984. The Evolution of Co-operation, New York: Basic Books, Inc.

Bernoulli, D., 1954. Exposition of a New Theory on the Measurement of Risk. Econometrica, 22(1), pp.23-36.

Bogle, J.C., 2010. Restoring Faith in Financial Markets. The Wallstreet Journal. Available at: http://www.wsj.com/articles/SB10001424052748703436504574640523013840290 [Accessed September 3, 2015].

BP plc, 2014. Annual Report, Available at: http://www.bp.com/en/global/corporate/investors/annual-reporting.html [Accessed September 3, 2015]. 
Caldecott, B., Dericks, G., Mitchell, J., 2015. Stranded Assets and Subcritical Coal: The Risk to Companies and Investors, Available at: http://www.smithschool.ox.ac.uk/researchprogrammes/stranded-assets/publications.php [Accessed January 24, 2016].

Caldecott, B., Horwath, N., McSharry, P., 2013. Stranded Assets in Agriculture: Protecting Value from Environment-related Risks, Available at: http://www.smithschool.ox.ac.uk/researchprogrammes/stranded-assets/publications.php [Accessed January 24, 2016].

Carbon Tracker Initiative, 2013. Unburnable Carbon 2013: Wasted capital and stranded assets, Available at: http://www.carbontracker.org/our-work/ [Accessed April 3, 2015].

Carbon Tracker Initiative, 2014. Carbon supply cost curves: oil capital expenditures, Available at: http://www.carbontracker.org/our-work/ [Accessed April 3, 2015].

CERES, 2015. CERES - Shareholder Resolutions. Available at: http://www.ceres.org/investornetwork/resolutions [Accessed September 3, 2015].

Clark, G., Feiner, A. \& Viehs, M., 2014. Stockholder to Stakeholder, Smith School of Enterprise and the Environment. Available at: http://www.smithschool.ox.ac.uk/library/index.php [Accessed April 3, 2015].

Covington, H. \& Thamotheram, R., 2015a. The Case for Forceful Stewardship (Part 1), Available at: https://preventablesurprises.com/programmes/climate-change/ [Accessed September 3, 2015].

Dawes, R.M., 1980. Social Dilemmas. Annual Review of Psychology, 31(1), pp.169-193.

Dimson, E., Karakas, O. \& Li, X., 2012. Active Ownership. Review of Financial Studies, Forthcoming, (December), pp.1-48. Available at: http://papers.ssrn.com/abstract=2154724 [Access November 5, 2015].

Eccles, R.G., loannou, I. \& Serafeim, G., 2012. The Impact of Corporate Sustainability on Organizational Processes and Performance. Management Science, Forthcoming. Available at: http://papers.ssrn.com/sol3/papers.cfm?abstract_id=1964011 [Accessed November 5, 2015].

Farrar, J., 2015. Fossil fuel divestment is not the way to reduce carbon emissions. The Guardian. Available at: http://www.theguardian.com/commentisfree/2015/mar/25/wellcome-trustfossil-fuel-divestment-not-way-reduce-carbon-emissions [Accessed April 3, 2015].

Faust, D., 2013. Fossil Fuel Divestment Statement. Harvard University. Available at: http://www.harvard.edu/president/fossil-fuels [Accessed September 3, 2015].

Fehr, E. \& Fischbacher, U., 2003. The nature of human altruism. Nature, 425(6960), pp.785-791.

Gibbons, R., 1992. A Primer in Game Theory, Harlow: Pearson Education Limited.

Goeree, J.K. \& Holt, C. a, 1999. Stochastic game theory: for playing games, not just for doing theory. Proceedings of the National Academy of Sciences of the United States of America, 96(19), pp.10564-10567. 
gofossilfree.org, 2015. Commitments. gofossilfree.org. Available at: http://gofossilfree.org/commitments/ [Accessed September 22, 2015].

Goodman, A. \& Fields, R.R.W., 2015. Board-Shareholder Engagement: Current \& Future Trends. Ethicalboardroom.com. Available at: http://ethicalboardroom.com/activism/boardshareholder-engagement-current-future-trends/ [Accessed May 8, 2015].

Haldane, A.G. \& Davies, R., 2011. The Short Long - Speech. Available at: http://www.bankofengland.co.uk/archive/Documents/historicpubs/speeches/2011/speech495 .pdf [Accessed September 3, 2015].

Hansson, S.O., 2005. Decision Theory, Available at: http://web.science.unsw.edu.au/ stevensherwood/120b/Hansson_05.pdf [Accessed September 3, 2015].

Hardin, G., 1968. The Tragedy of the Commons. Science, 162(June), pp.1243-1248.

Harsanyi, J.C., 1973. Games with randomly disturbed payoffs: A new rationale for mixed-strategy equilibrium points. International Journal of Game Theory, 2(1), pp.1-23.

Howard, N., 1971. Paradoxes of Rationality: Theory of metaames and political behavior, Cambridge, Mass.: MIT Press.

Ishibuchi, H. \& Namikawa, N., 2005. Evolution of Iterated Prisoner's Dilemma Game Strategies in Structured Demes under Random Pairing in Game-Playing. IEEE Trans. on Evolutionary Computation, 9(6), pp.552-561.

Janssen, M. a., 2008. Evolution of cooperation in a one-shot Prisoner's Dilemma based on recognition of trustworthy and untrustworthy agents. Journal of Economic Behavior and Organization, 65(3-4), pp.458-471.

Johnson, S, 2015. Compulsory stewardship by passive managers moves closer. The Financial Times. Available at: http://www.ft.com/cms/s/0/3917d0d0-e812-11e4-894a00144feab7de.html\#axzz3yFP6jymf [Accessed January 24, 2016].

Kanazawa, S. \& Fontaine, L., 2013. Intelligent people defect more in a one-shot prisoner's dilemma game. Journal of Neuroscience, Psychology, and Economics, 6(3), pp.201-213.

Kay, J., 2012. The Kay review of the UK equity market and long-term decision making. Available at: https://www.gov.uk/government/publications/kay-review-of-uk-equity-markets-and-longterm-decision-making-implementation-progress-report [Accessed April 3, 2015].

Kim, J. \& Schloetzer, J.D., 2013. Global Trends in Board-Shareholder Engagement, The Conference Board. Available at: https://www.conferenceboard.org/publications/publicationdetail.cfm?publicationid=2618 [Accessed September 3, 2015].

Komorita, S.S., 1976. A model of the N-person dilemma-type game. Journal of Experimental Social Psychology, 12(4), pp.357-373. 
Kreps, D.M. et al., 1982. Rational cooperation in the finitely repeated prisoners' dilemma. Journal of Economic Theory, 27(2), pp.245-252.

Kuhn, S., 2014. Prisoner's Dilemma. The Stanford Encyclopedia of Philosophy. Available at: http://plato.stanford.edu/entries/prisoner-dilemma/ [Accessed September 3, 2015].

Lewis, M.C. \& Voisin, S., 2014. Stranded assets, fossilised revenues, Kepler Cheuvreux. Available at: https://www.keplercheuvreux.com/pdf/research/EG_EG_253208.pdf [Accessed April 3, 2015].

Local Authority Pension Fund Forum (LAPFF) 2015. And Statoil Makes Three as Transatlantic Gap Grows. News. Available at: http://www.lapfforum.org/news/and-statoil-makes-three-astransatlantic-gap-grows [Accessed January 24, 2016].

Aiming For 'A' Investor Coalition 2015. BP Shell AGM 2015 Institutional Co-Filing Group 2nd Feb 2015 Final. Available at:

http://www.churchinvestorsgroup.org.uk/system/files/documents/James\%20Corah/BP\%20Sh ell\%20AGM\%202015\%20Institutional\%20Cofiling\%20Group\%202nd\%20Feb\%202015\%20Final.pdf [Accessed January 24, 2016].

Manhart, K. \& Diekmann, C.A., 1989. Cooperation in 2- and N-Person Prisoner's Dilemma Games: A Simulation Study. Analyse \& Kritik, (September), pp.134-153.

McCall, A.L. \& Larker, D.F., 2014. Researchers: The Power of Proxy Advisory Firms. Insights by Stanford Business. Available at: https://www.gsb.stanford.edu/insights/researchers-powerproxy-advisory-firms [Accessed September 3, 2015].

McGlade, C. \& Ekins, P., 2015. The geographical distribution of fossil fuels unused when limiting global warming to $2^{\circ} \mathrm{C}$. Nature, 517(7533), pp.187-190.

McKibben, B., 2012. Global Warming's Terrifying New Math. The Rolling Stone. Available at: http://www.rollingstone.com/politics/news/global-warmings-terrifying-new-math-20120719 [Accessed April 3, 2015].

Mesterton-Gibbons, M., 2000. An Introduction to Game-Theoretic Modelling, 2nd ed., American Mathematical Society.

Miller, J.H., 1996. The coevolution of automata in the repeated prisoner' s dilemma. Journal of Economic Behavior and Organization, 29(1), pp.87-112.

Nash, J., 1950. Equilibrium Points in N-Person Games. Proceedings of the National Academy of Sciences of the United States of America, 39(1), pp.48-49.

Neumann, J. Von \& Morgenstern, O., 1944. Theory of Games and Economic Behavior 60th Anniv., Princeton: Princeton University Press.

Nordhaus, B.W., 2015. Climate Clubs: Overcoming Free-riding in International Climate Policy. The American Economic Review, 105(4), pp.1339-1370.

Orsagh, M., 2014. Shareholder Engagement: Bridging the Gap Between Boards and Investors. CFA Institute. Available at: http://blogs.cfainstitute.org/marketintegrity/2014/03/26/shareholderengagement-bridging-the-divide-between-boards-and-investors/ [Accessed May 8, 2015]. 
Paul Spedding, Mehta, K. \& Robins, N., 2013. Oil \& carbon revisited- Value at risk from "unburnable" reserves, HSBC. Available at: http://daily.swarthmore.edu/wpcontent/uploads/2013/02/HSBCOilJan13.pdf [Accessed April 3, 2015].

Pettit, P. \& Sugden, R., 1989. The Backward Induction Paradox. The Journal of Philosophy, 86(4), pp.169-182.

PIRC, 2015. BP AGM - Who's Next to Aim for A? Available at: http://pirc.co.uk/pircnews/bp-agmwho-is-next-to-aim-for-a [Accessed September 3, 2015].

Pothos, E.M. et al., 2011. Understanding cooperation in the Prisoner's Dilemma game. Personality and Individual Differences, 51(3), pp.210-215.

PRI, 2015. PRI - Clearinghouse. Available at: http://www.unpri.org/areas-of-work/clearinghouse/ [Accessed September 3, 2015].

PWC, 2015. Key issues: Shareholder Engagement. Center for Board Governance. Available at: http://www.pwc.com/us/en/corporate-governance/shareholder-engagement.jhtml [Accessed May 8, 2015].

Ray, D. \& Vohra, R., 1999. A Theory of Endogenous Coalition Structures. Games and Economic Behavior, 26, pp.286-336.

Reinsvold, C.H., 2015. The Oil and Gas CEO. Oil\&Gas Financial Journal, 11(9). Available at: http://www.ogfj.com/articles/print/volume-11/issue-9/features/the-oil-and-gas-ceo.html [Accessed September 3, 2015].

Rezaei, G., Kirley, M. \& Pfau, J., 2009. Evolving cooperation in the N-player prisoner's dilemma: A social network model. Lecture Notes in Computer Science, 5865 LNAl, pp.43-52.

Royal Dutch Shell plc, 2015. Annual Report 2014, Available at: http://www.shell.com/global/aboutshell/media/reports-publications.html [Accessed September 3, 2015].

Shenoy, P.P., 1979. On coalition formation: a game-theoretical approach. International Journal of Game Theory, 8(3), pp.133-164.

Skancke, M. et al., 2014. Fossil-Fuel Investments in the Norwegian Government Pension Fund Global: Addressing Climate Issues Through Exclusion and Active Ownership, Expert Group appointed by the Norwegian Ministry of Finance.

Smith, J.M., 1982. Evolution and the Theory of Games, Cambridge: Cambridge University Press.

Standard \& Poor's, 2013. What A Carbon-Constrained Future Could Mean For Oil Companies' Creditworthiness, Standard \& Poor's. Available at: http://www.standardandpohttps//www.standardandpoors.com/ratings/articles/en/eu/?article Type=PDF\&assetID=1245348784590name2=Content Disposition\&blobheadervalue1=application/pdf\&blobkey=i [Accessed April 3, 2015]. 
Standard \& Poor's, 2015. How Environment and Climate Risk Factor into Global Corporate Ratings, Standard \& Poor's. Available at: https://www.environmental-

finance.com/content/research/how-environmental-and-climate-risks-factor-into-globalcorporate-ratings.html [Accessed January 1, 2016].

Szilagyi, M.N., 2003. An Investigation of N-person Prisoners Dilemmas. Complex Systems, 14, pp.155-174.

The Economist Intelligence Unit, 2015. The Cost of Inaction: Recognising the value at risk from climate change, Available at: http://www.economistinsights.com/financialservices/analysis/cost-inaction [Accessed September 3, 2015].

Total S.A., 2015. Total Annual Report, Available at: http://www.total.com/en/media/news/pressreleases/2014-annual-reports [Accessed September 3, 2015].

Vyrastekova, J. \& Funaki, Y., 2010. Cooperation in a sequential N-person prisoner's dilemma: The role of information and reciprocity. (Unpublished Work). Available at: www.ru.nl/publish/pages/516298/nice_10-103.pdf [Accessed September 3, 2015].

Wong, S., 2010. Why stewardship is proving elusive for institutional investors. Butterworths Journal of International Banking and Financial Law, July/Augus, pp.406-411.

Yahoo, 2015. Yahoo Finance. Available at: https://uk.finance.yahoo.com/ [Accessed September 3, 2015].

Yahoo! Finance, 2015a. Chevron Corporation (CVX). Available at: http://finance.yahoo.com/q/mh?s=CVX+Major+Holders [Accessed September 3, 2015].

Yahoo! Finance, 2015b. Exxon Mobil Corporation (XOM). Available at: http://finance.yahoo.com/q/mh?s=XOM+Major+Holders [Accessed September 3, 2015]. 


\section{Appendix A: Development of a 1v1 Prisoner's Dilemma}

The canonical Prisoner's Dilemma (PD) was initially developed by Dresher \& Flood in 1950 to model strategic options during the cold war (Aumann et al. 1964). The PD's characteristic traits make it one of the most written-of social dilemmas, with interest spanning from economics, psychology, and political science (Dawes 1980), evolutionary biology (Smith 1982), and artificial intelligence and machine learning (Miller 1996). A single-shot prisoner's dilemma is considered with elements described by Table 4 . The notation and methodology used herein are typical of any introductory level game theory study (e.g. Gibbons 1992; Mesterton-Gibbons 2000).

$$
\begin{array}{rc}
\text { Table 4 Elements of a single-shot PD } \\
\text { Game } & g=g_{i}(A, v) \\
\text { Players } & i=\left\{\begin{array}{l}
1 \\
2
\end{array}\right. \\
\text { Action Space } & A_{i}=[\text { COOPERATE, DEFECT }]=[C, D] \\
\text { Pure Strategy } & a_{i} \in A_{i} \\
\text { Pure Strategy Payoffs } & v_{i}=f\left(a_{i}, a_{-i}\right)
\end{array}
$$

Pure strategy payoffs are given in matrix form in Figure 2 below, subject to the constraint of Equation 1.

Player 2

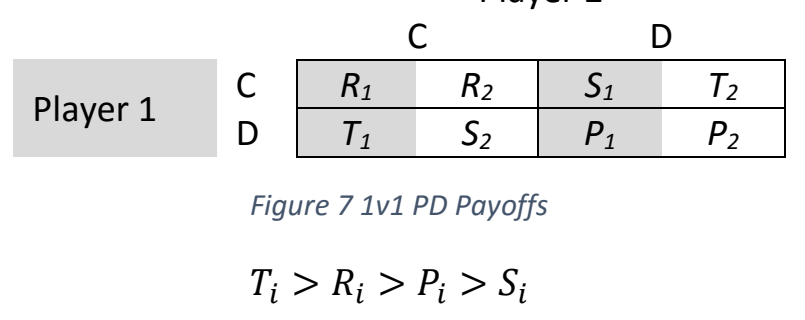

The Nash Equilibrium (NE) of this matrix form game is (D,D). Even with asymmetric payoffs, as long as the ordinal nature of each player's payoffs holds, the NE remains (D,D). Relaxing the order of player i's payoffs results in a common knowledge PD, where player $i$, knowing the other's payoffs, will still choose mutual defection, provided $P_{i}>S_{i}$ (Kuhn 2014). The one-shot nature of this game lends itself better to study in fields of psychology and sociology, with research on topics like intelligence (e.g. Kanazawa \& Fontaine, 2013), trustworthiness (e.g. Janssen, 2008), or personality (e.g. Pothos, Perry, Corr, Matthew, \& Busemeyer, 2011). 


\section{Appendix B: Development of a 1V1 Iterated PD}

The single-shot game developed in Appendix A is capable of modelling many interactions where two agents interact only once. The uncooperative $N E(D, D)$ is dissatisfying both for its generally negative connotation and its failure to predict the cooperative equilibria regularly observed between real individuals and organizations (Fehr \& Fischbacher 2003; Pothos et al. 2011). Repeated interactions between agents have the potential to create conditions of trust and mutual cooperation, resulting in improvements in both private outcomes and overall system efficiency (Axelrod 1984; Kreps et al. 1982). The repeated PD is called the iterated prisoner's dilemma (IPD).

\section{Deterministic IPD}

In the IPD, players engage in a PD game which repeats for multiple rounds. Elements of a deterministic IPD are described in Table 5 below. A deterministic IPD is characterized by the pure strategies and payoffs of the players being common knowledge.

Table 5 Elements of a deterministic IPD

Game
Game Length
Strategy
Discount Factor
Payoff

Game

Discount Factor

$$
\begin{gathered}
G=G(s, V, \tau) \\
\tau=[1, \infty] \\
s_{i}=\left(a_{i, 1}, \ldots a_{i, t}, \ldots a_{1, \tau}\right) \\
\delta_{i}=[0,1) \\
V_{i}=V\left(\delta_{i}, s_{i}, s_{-i}\right)
\end{gathered}
$$

The payoff of the players may be additive, per Equation 2, or averaged over multiple rounds.

$$
V_{i}=\sum_{t=0}^{\tau} v\left(a_{i, t}, a_{-i, t}\right)
$$

The strategy space for players is now much more sophisticated, with players able to choose from a variety of rules or sequences of cooperation or defection. Some simple strategies are shown in Table 6. Robert Axelrod (1980) first proposed an open-entry strategy competition where submitted algorithms would compete in an iterated Prisoners' Dilemma. Axelrod explored the characteristics of successful strategies and drew comparisons to real-life examples of sustained mutual cooperation.

Table 6 Simple Iterated Prisoners' Dilemma Strategies

\begin{tabular}{ll}
\hline Strategy & Description \\
\hline Grim Trigger & Cooperate until opponent defects, then always defect. \\
Tit-For-Tat & Always reciprocate opponent's last move. \\
Pavlov & On a payoff of P or S, change strategies. \\
\hline
\end{tabular}

For IPDs of any finite length with complete and perfect knowledge, a single Nash Equilibrium exists. Players use reverse induction to determine that the strategy to always defect strictly dominates all other strategies. While theoretically sound, this equilibrium is unsatisfying, especially at large numbers of iteration (Pettit \& Sugden 1989). Similarly, for IPDs of infinite or indeterminate length, no single Nash Equilibrium strictly dominates all others. Players must play strategies which are best responses to each other. The following development of the IPD is typical to introductory level game theory (e.g. Gibbons 1992; Mesterton-Gibbons 2000).

For an IPD of infinite or indeterminate length, Nash Equilibria may be identified with the inclusion of the discounting factor, $\delta$. The discounting factor represents either the relative value of a payoff 
Following Axelrod's successful computer tournament in 1980, an ongoing annual competition pits a wide range of strategies against each other. Strategies now range in complexity from the original simple strategies as in Table 6, to sophisticated strategies using probabilistic models.

\section{Mixed-Strategy IPD}

Deterministic IPDs involve explicit assumptions about the cooperative rational nature of the players, and only have cooperative NE for infinite or indeterminate length games. To examine the conditions which best enable routine cooperation from self-interested players, a mixed-strategy IPD is more useful. Following Harsanyi (1973), mixed-strategy weighting can be used to represent belief spaces, allowing the development of Bayesian Nash Equilibrium (BNE). These beliefs may be updated as Bayesian inferences developed from sequential behaviour, as in Georee \& Holt (1999). Thus a mixedstrategy IPD adds the elements of Table 7 to the elements of a deterministic IPD and single-shot PD.

Table 7 Elements of a mixed-strategy IPD

$$
\begin{array}{rc}
\text { Subgame History } & H_{t-1}=\left\{a_{1,1}, a_{2,1} ; a_{1,2}, a_{2,2} ; \ldots a_{1, t-1}, a_{2, t-1}\right\} \\
\text { Discount Factors } & \delta_{i}=(01) \\
\text { Beliefs } & \theta_{s, i}=\left\{\begin{array}{c}
\theta\left(H_{t-1,-i}\right) \\
1-\theta\left(H_{t-1,-i}\right)
\end{array}\right. \\
\text { Foresight } & L_{i} \\
\text { Memory } & Q_{i} \\
\text { Expected Payoffs } & \pi^{e}{ }_{i}=F\left(V_{i}, \delta_{i}, \theta_{i}, L_{i}\right)
\end{array}
$$

The pure strategy chosen by a player at time $t$ is determined randomly by the mixed-strategy expected payoffs of each pure strategy, per Equation 6.

$$
s_{i}=\operatorname{rand}\left\{\begin{array}{c}
C \\
D \text { with } P_{C}=P\left(\pi^{e}{ }_{C}, \pi^{e}{ }_{D}\right) \\
P_{D}=1-P_{C}
\end{array}\right.
$$


An evolutionary algorithm, as in Goeree \& Holt (Goeree \& Holt 1999), is used to weight expected payoffs into probabilities, per Equation 7. A relaxing factor, $\mu$, can be adjusted to suit the importance of payoffs in determining the random development of player actions.

$$
P_{C}=\frac{e^{\pi^{e} C / \mu}}{e^{\pi^{e} C / \mu}+e^{\pi^{e} D / \mu}} \text { with } \mu=(0, \infty)
$$

Expected payoffs are the mixed-strategy payoffs developed for a bounded horizon of $L$ periods per Equation 8 . Mixed-strategy payoffs are weighted by common knowledge beliefs $\theta_{s, i}$ (of a player $i$ to play a strategy $s)$.

$$
\pi_{s, i}^{e}=\sum_{t=t_{0}}^{t_{0}+L} \sum_{i=1,2} \sum_{s=C, D} \theta_{s, i} * \theta_{s,-i} * v_{i}\left(s_{i}, s_{-i}\right) * \delta^{t-t_{0}}
$$

Common knowledge beliefs, are updated after each round. The beliefs are updated based on the number of times a player adopts strategy per Equation 9. By updating beliefs based on observed actions, cooperative actions increase the probability of mutual cooperation and defection actions increase the probability of mutual defection. The history of observed actions is limited by the memory of the player.

$$
\theta_{s, i}=\frac{\operatorname{count}\left(H\left(Q_{i}\right)=s\right)}{\operatorname{size}\left(H\left(Q_{i}\right)\right)}
$$

The sequentially updating beliefs result in a Markov chain of mixed probabilities and payoff states per Equation 10.

$$
\begin{gathered}
\pi_{s, i}^{e}=\delta^{0} \sum\left\{\begin{array}{l}
\theta_{C,-i, 0} * v_{i}(s, C) \\
\theta_{D,-i, 0} * v_{i}(s, D)
\end{array}\right\}+\delta^{1} \sum\left\{\begin{array}{l}
\theta_{C, i, 1} * \theta_{C,-i, 1} * v_{i}(C, C) \\
\theta_{D, i, 1} * \theta_{C,-i, 1} * v_{i}(D, C) \\
\theta_{C, i, 1} * \theta_{D,-i, 1} * v_{i}(C, D) \\
\theta_{D, i, 1} * \theta_{D,-i, 1} * v_{i}(D, D)
\end{array}\right\}+\cdots \\
+\delta^{L} \sum\left\{\begin{array}{l}
\theta_{C, i, L} * \theta_{C,-i, L} * v_{i}(C, C) \\
\theta_{D, i, L} * \theta_{C,-i, L} * v_{i}(D, C) \\
\theta_{C, i, L} * \theta_{D,-i, L} * v_{i}(C, D) \\
\theta_{D, i, L} * \theta_{D,-i, L} * v_{i}(D, D)
\end{array}\right\}
\end{gathered}
$$

The updating of beliefs for each round, $\theta_{s, i, t}$, requires a result of the previous round. A Monte Carlo method is used to randomly generate a strategy pair for each round according to probabilities established by mixed beliefs at each round, illustrated by Equation 11.

$$
s_{i}, s_{-i}=\operatorname{rand}\left\{\begin{array}{lr}
C, C & P_{C, C}=\theta_{C, i, L} * \theta_{C,-i, L} \\
D, C & P_{D, C}=\theta_{D, i, L} * \theta_{C,-i, L} \\
C, D & \text { with } P_{C, D}=\theta_{C, i, L} * \theta_{D,-i, L} \\
D, D & P_{D, D}=\theta_{D, i, L} * \theta_{D,-i, L}
\end{array}\right.
$$




\section{Appendix C: Development of an NvN IPD}

The NvN IPD (NIPD) is an abstraction of the 1V1 IPD which has application to a greater set of social coordination and commons problems. The NIPD can be used to describe challenges with pollution, public services, energy and water conservation, etc; all situations where an individual receives a higher payoff for any defective action, but all payoffs are higher with collective cooperation. Due to the larger number of players involved, conditions for cooperation are often more elusive than in the IPD. In the NIPD, harm from defection is dispersed among multiple players, defection is more anonymous, and any reinforcing punishment strategies directed against a defector have negative externalities on all other players (Dawes 1980).

Many authors have studied the NIPD. For large N, an uncooperative equilibrium of self-optimizing agents develops quickly (e.g. Komorita 1976). In order to provide non-trivial results, authors seek mechanisms which induce cooperation in the population. Some studies use compound games (i.e. large games featuring many $1 \mathrm{v} 1$ subgames) and spatial considerations to inspire cooperation (Axelrod 1984; Ishibuchi \& Namikawa 2005; Rezaei et al. 2009). Other use evolutionary and personality diversities (whether in behaviour or payoffs) to find conditions which induce cooperation (Axelrod 1984; Szilagyi 2003; Manhart \& Diekmann 1989).

Calculation of behaviour and equilibria in the NIPD can be an NP-hard optimization problem. Dawes (Dawes 1980) suggests that elements of knowledge (e.g. communication, public disclosure), morality, and trust have the greatest impact on the development of cooperation in real social dilemmas.

\section{Deterministic NIPD}

An NIPD based on Vyrastekova (2010) and Manhart \& Diekmann (1989) is developed here. Both authors use agent personalities in the form of asymmetric payoffs to explore cooperation. Elements of the NIPD are described in Table 8.

$$
\begin{array}{rc} 
& \text { Table 8 Elements of an NIPD } \\
\text { Game } & g=g_{i}(A, v) \\
\text { Players } & i=1,2, \ldots, N \\
\text { Action Space } & A_{i}=[\text { COOPERATE, DEFECT }]=[C, D] \\
\text { Pure Strategy } & a_{i} \in A_{i} \\
\text { Pure Strategy Payoffs } & v_{i}=f\left(a_{i}, k\right)
\end{array}
$$

As in the IPD, players face the choice to either cooperate or defect. In the NIPD, the reward for cooperating grows with the number of players cooperating. However, for the same number of players cooperating, the defectors receive a greater payoff. Equations 13-16 describe the payoff conditions of the NIPD.

$$
\begin{gathered}
\text { with } k=\frac{N_{C}}{N}, k^{\prime}=\frac{N_{C}+1}{N} \\
V\left(D, k^{\prime}\right)>V(D, k) \\
V\left(C, k^{\prime}\right)>V(C, k) \\
V\left(C, k^{\prime}\right)<V(D, k) \\
V(C, k=1)>V(D, k=0)
\end{gathered}
$$

With payoffs $R$ for cooperation and $T$ for defection, Figure 8 shows how, given Equation 15 above, $D$ dominates $C$ for any $k$. The Nash Equilibrium of the NIPD is sustained defection by all players. As $N$ becomes large, the threat of future sanctions is insufficient to ensure conditions for cooperation. Any 
credible threat against a defecting player is diluted with negative externalities to other players, making the conditions for cooperation more difficult.

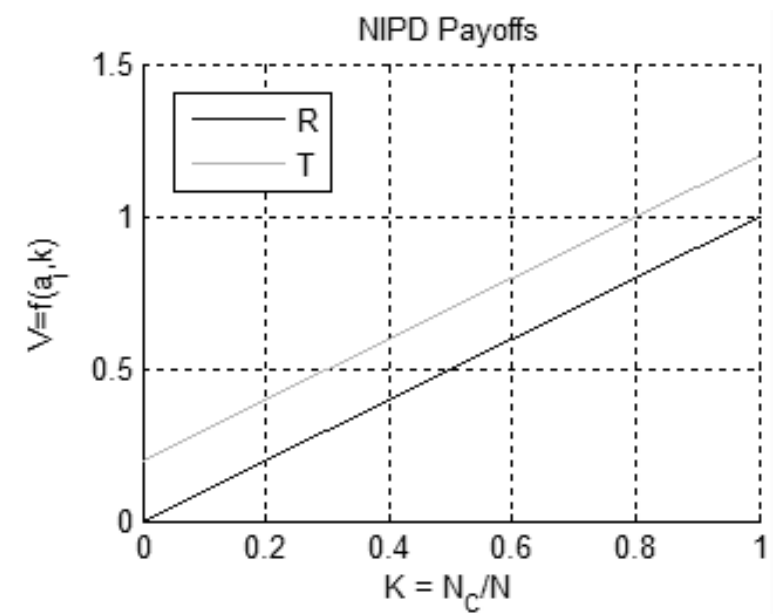

Figure 8 Pure NIPD Payoffs.

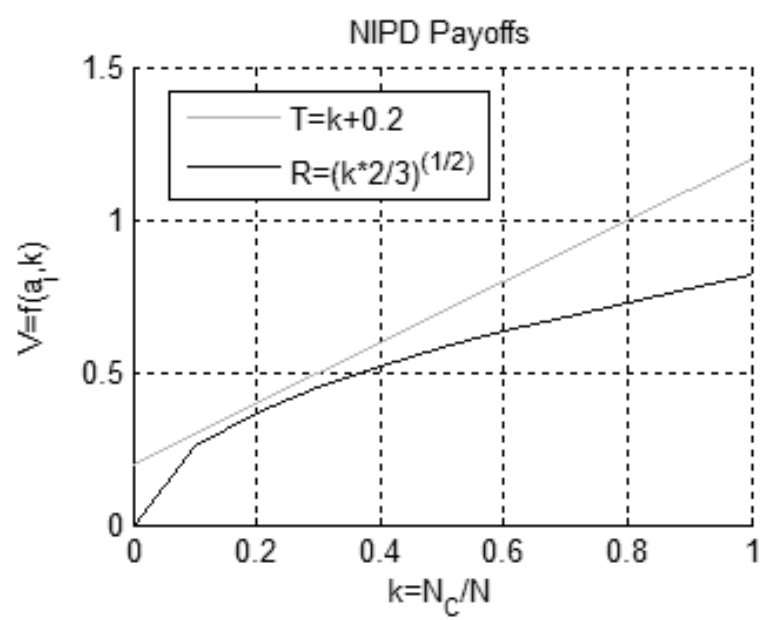

Figure 9 Relaxed NIPD Payoffs, example.

To develop useful cooperation scenarios from the NIPD, the condition of Equation 15 will be relaxed to Equation 17 below. To appropriately model the commons and freeriding problems the NIPD simulates, the payoff for additional cooperation will have diminishing returns as in Figure 9.

$$
V(C, k)<V(D, k)
$$

With symmetric payoffs the Nash Equilibrium occurs at some deterministic $k>0$. However with asymmetric mixed strategy payoffs based on each player's individual beliefs, the Bayesian Nash Equilibrium need not occur at a deterministic value of $k$. This allows for the development of more unique insight and less prescriptive model behaviour.

\section{Mixed Strategy NIPD}

The NIPD may also be developed in cases where payoffs are asymmetric. Payoffs $R$ and $T$, for cooperation and defection respectively, may be weighted by an individual factor $U_{j}$. Payoff conditions described as above still hold, with a new $K$ described in 18 . Equations 19 and 20 describe asymmetric payoffs $R_{j}$ and $T_{j}$.

$$
\begin{aligned}
\text { with } K_{i}= & \frac{\sum_{j=1}^{N_{C}} U_{j \neq i}}{\sum_{j=1}^{N} U_{j}}, K_{i}{ }^{\prime}=\frac{\sum_{j=1}^{N_{C}} U_{j \neq i}+U_{i}}{\sum_{j=1}^{N} U_{j}} \\
& v_{i}\left(C, K_{i}\right)=R_{i}=\alpha K_{i}{ }^{\gamma} \\
& v_{i}\left(D, K_{i}\right)=T_{i}=K_{i}+\beta
\end{aligned}
$$

As in the mixed-strategy IPD, players develop an expected payoff based on their beliefs of the other players actions. Elements of a mixed-strategy NIPD are given in Table 9.

Table 9 Additional Elements of a mixed-strategy NIPD

Subgame History

Beliefs

Expected Payoffs

$$
\begin{gathered}
H_{t-1}=\left\{a_{i, 1}, a_{j \neq i, 1} ; a_{i, 2}, a_{j \neq i, 2} ; \ldots a_{i, t-1}, a_{j \neq i, t-1}\right\} \\
\theta_{s, i}=\left\{\begin{array}{c}
\theta\left(H_{t-1,-i}\right) \\
1-\theta\left(H_{t-1,-i}\right)
\end{array}\right. \\
\pi^{e}{ }_{i}=F\left(v_{i}, \theta_{i}\right)
\end{gathered}
$$


Mixed-strategy expected payoffs are given by Equations 21 and 22 below.

$$
\begin{gathered}
\pi_{i}^{e}\left(C, K_{i}\right)=\alpha{K_{i}}^{\prime \gamma}=\alpha\left[\frac{U_{i}}{\sum_{j=1}^{N} U_{j}}+\frac{1}{\sum_{j=1}^{N} U_{j}} \sum_{j=1}^{N} U_{j \neq i}\left(P_{C}=\theta_{C, j}\right)\right]^{\gamma} \\
\pi^{e}{ }_{i}\left(D, K_{i}\right)=K_{i}+\beta=\left[\frac{1}{\sum_{j=1}^{N} U_{j}} \sum_{j=1}^{N} U_{j \neq i}\left(P_{C}=\theta_{C, j}\right)\right]+\beta
\end{gathered}
$$

The expected payoffs are now dependent on a joint probability distribution of $N$ discrete variables, each with the value $U_{j}$ or 0 according to a probability $\theta_{C, j}$. To determine the probability density function deterministically would require the evaluation of $2^{N}$ states, a computationally-demanding task as $N$ gets large. A Monte-Carlo method is used to sample states of $U_{j}$ to develop a probability density function with sufficient confidence. Expected payoffs are calculated from the probability density function and players choose their action with the same evolutionary algorithm as in Equation 7. 


\section{Figure Captions}

Figure 1 Decision Theory Fields. Adapted from Mesterton-Gibbons 2000.

Figure 2 1v1 Prisoner's dilemma payoffs in matrix form with Nash Equilibrium underlined.

Figure 3 Modelled dependence of mutual cooperation on payoff and discount factors.

Figure 4 Modelled dependence of mutual cooperation on degree of foresight and history memory.

Figure 5 Freeriding temptation under various payoff profiles.

Figure 6 Cooperation dependence on agent weighting subject to various defection payoffs.

Figure 7 1v1 PD Payoffs.

Figure 8 Pure NIPD Payoffs.

Figure 9 Relaxed NIPD Payoffs, example. 